\title{
Physical and Soft Sensor Technologies for Wastewater Quality Management
}

\author{
Nor Hana Mamat ${ }^{\text {a,c }}$, Saliza Ramli ${ }^{\text {a,d }}$, Nor Arymaswati Abdullah ${ }^{\text {a,e }}$, Samia Khan ${ }^{\text {b }}$ and \\ Chandima Gomes ${ }^{\text {a* }}$
}

\footnotetext{
${ }^{a}$ Department of Electrical Engineering, Faculty of Engineering, Universiti Putra Malaysia, Serdang, 43400, Selangor, Malaysia

${ }^{b}$ Department of Computer and Communications Engineering, Universiti Putra Malaysia, Serdang, 43400, Selangor, Malaysia

${ }^{c}$ Faculty of Electrical and Automation Engineering Technology, TATI University College, 24000 Kemaman, Terengganu, Malaysia

${ }^{d}$ Faculty of Engineering Technology, Universiti Teknikal Malaysia Melaka, 75450 Ayer Keroh, Malacca, Malaysia

${ }^{e}$ Technical Support Division, Malaysian Nuclear Agency, 43000 Kajang, Selangor, Malaysia
}

Received: 21 November 2017; Accepted: 09 August 2018; Published: 08 November 2018

\begin{abstract}
Physical sensors are used mostly to detect sludge and odour in wastewater. Black box modelling or dataderived model using the correlation of input-output parameters is the preferred method as we have assessed. This is due to the non-complex approach of such models as opposed to model-driven, mechanistic models. The latter is hard to be adopted for soft-sensor development due to the inherent complexities and uncertainties. The commonest methods for soft sensor model development are ANN and ANFIS. Many other improvements of these methods are achieved by combining with other techniques to enhance the prediction performance of the soft sensors. Accuracy and precision of data collected for soft sensor modelling has become a vital concern at present to ensure the reliability of wastewater quality indices predicted by the soft sensors. Reduction of the level of reliability of the sensor system in monitoring and controlling of WWTPs would lead to serious lapses in the wastewater quality management. In this backdrop we recommend SEVA soft sensor as one of the best potential solutions which could be offered by the existing technologies.
\end{abstract}

Index Terms: Wastewater quality, physical sensor, soft sensor, treatment plant, selectivity, sensitivity.

(C) 2018 Published by MECS Publisher. Selection and/or peer review under responsibility of the Research Association of Modern Education and Computer Science.

\footnotetext{
* Corresponding author. Tel.: +60102777895 fax: +60 389466311

E-mail address: chandima.gomes@gmail.com
} 


\section{Introduction}

Wastewater from both industrial and municipal origins could either be recycled or discharged into large water bodies. However, such process should follow stringent environmental laws set forth in many countries at present. For either of the processes, physical and chemical parameters of effluents in wastewater treatment plants (WWTP) should satisfy a number of constraints and conditions which is usually achieved through a preset quality management pathway or algorithm. The quality of wastewater is evaluated by the measurement of many parameters. The most widely used such parameters at present are; biological oxygen demand (BOD), chemical oxygen demand (COD), total organic carbon (TOC), total suspended solids (TSS), oxygen uptake rate (OUR), $\mathrm{pH}$ value, and levels of phosphorus and nitrogen compounds [1].

Management of WWTP is typically based on four concepts that should be physically implemented; Development of an appropriate process model, selection, and application of the optimum number of suitable sensors that provide relevant and accurate online data, adequate monitoring and quality control strategies, actuators that implement the controller output [2]. In this step-ladder, sensors play a vital role as the failure of a sensor to provide reasonable output could completely off-balance the entire process irrespective of the process model.

Typically, there are four basic types of sensors that are employed in wastewater management plants; Chemical sensors, biosensors, physical sensors and soft sensors [3]. Their main objective is to regularly monitor various contaminants, both suspended particles and dissolved substances in the effluent. Despite the development of many sensors for this purpose during the last few decades, until now, a comprehensive monitoring system for WWTP which can provide fast, continuous, and highly accurate information is a challenge to be overcome. The large spectrum of contaminants released by various industrial processes, the variation of sensitivity and response time of sensors for different contaminants and the need for automated monitoring device due to the requirement of continuous data stand as barriers to overcome in the development of an ideal monitoring system. Such challenge opens the doors for improvement and improvisation of the existing sensor technologies apart from inventing new technologies.

During the last decade, many new technologies have emerged in the science of sensor. Many of them may be adopted for wastewater quality management. However, due to the fast development of sensor technologies during the recent past, many scientists may have overlooked the new knowledge emerged beyond their own scientific circles. Such information may provide vital information for developing better techniques [4]-[6]. This paper intends to review a part of the sensor technologies developed during the last few years that can be applicable in wastewater quality management; physical and soft sensors; to serve this scientific need.

\section{Physical Sensors}

Physical sensors have contributed in many fields such as various industries, aerospace, biomedical, engineering, and military. They play a vital role in our day-to-day life. Some widely used physical sensors include inductive sensors, resistance sensors, and displacement sensors. These sensors measure the physical parameters such as displacement, velocity, temperature, pressure, position, force, acceleration and flow rate. These physical sensors are placed typically at the input of the wastewater system in order to measure the physical parameters.

The physical phenomenon used by the sensor is classified on the basis of mechanical, optical, magnetic, thermal and few other properties. The quality of water is governed by several physical factors, apart from chemical and biological factors. The sensors for water quality management are employed for maintaining high levels of qualities these physical quantities. Depending on the physical method many sensors are available.

\subsection{Plastic Optic Fibre (POF) Sensors}

The POF sensor performs by associating the transmitted optical power with suspended solids in an anaerobic 
and high-impact slime over an extensive variety of fixations, typical for bioreactors, utilized in wastewater treatment $(0.1-8.6 \mathrm{~g} \mathrm{~L}-1)$. Fundamentally, fibre technology is more adaptable and less costly than many other modes. Plastic fibre optic links are produced using only one acrylic monofilament and are highly proficient when utilized with noticeable red status marker light sources. Plastic strands are by and large more financially viable than glass fibre optic links and in this manner, are appropriate for applications that need consistent flexing of the fibre.

Interestingly, plastic optical filaments utilize innocuous green or red light that does not adversely affect the eye. Thus, they may safely be introduced for domestic applications, as an inquisitive minor may not accidentally expose his eyes to hazardous intensities at visible range. Plastic optical filaments have a tendency to be thicker than glass optical strands, a millimeter or more, and could be taken care of without exceptional devices or systems.

The main impediment of POF is its low transfer speed, which restricts the information rate it can convey to around $200 \mathrm{Mbit} / \mathrm{s}$ for a $50 \mathrm{~m}$ connect. Be that as it may, an enhanced adaptation of straightforward stride list POF is evaluated file POF. This fibre defeats the data transfer capacity confinement yet has the inconvenience of higher cost and constrained temperature execution. In spite of these disadvantages, POF is the main decision when the connection length is short (most extreme $100 \mathrm{~m}$ ), when the framework must be tough, and when the required information rate is under $500 \mathrm{Mbit} / \mathrm{s}$.

The speed of data transfer can greatly be increased by using fibre optic sensors where the information is transferred via electromagnetic radiation in the visible range [7]. No other link-based information transmission medium offers the data transfer capacity with a low rate of bit mistake that fibre does [8]. Despite the rate of fibre establishment expenses are dropping, by as much as $60 \%$ a year, introducing fibre optic cabling is still moderately expensive. The test hardware commonly and generally utilized for routine electron-based systems is of no use in a fibre optic system and a purpose made test gear is frequently required for the maintenance of such system. Fiber communication links are exceedingly vulnerable to be accidentally damaged amid construction or development exercises. Wild animals can also bring harm to fibre optic links. Kevlar strengthening material of fibre link coats, especially engaging as settling material, may be used when fibre linked sensors are used under adverse surrounding conditions [9].

\subsection{LED UV fluorescence Sensors}

LED sensors were developed for the purpose of online monitoring. Various types of dissolved organic matter are found in drinking and wastewater effluents. The requirement for radical treatment is obvious for the removal of such unwanted organic contamination. LED UV fluorescence sensor is applicable in such situations for detecting contaminants.

Henderson et al [10] showed that spectral measurements, such as UV absorbance and fluorescence incorporated with dissolved organic matter (DOM) and dissolved organic carbon (DOC), could effectively be used in frequent online monitoring [10]. Further studies justified that UV indices, especially the absorbance at a specific wavelength, such as UV254 and UV272 and absorbance slope indices are linearly related to toxic disinfection byproducts [11], [12]. The series of inventions and discoveries since Henderson et al. [10] paved the way to a wide range of applications of fluorescence excitation-emission matrix (EEM) for characterization of DOM. Most of these applications are focused on protein-like and humic-like components [13]. In their recent studies Li et al. [14] clearly justified that high-performance size exclusion chromatography with multiUV absorbance and multi-emission fluorescence scans could successfully be applied to spectrally characterize samples from drinking water sources across Yangzi River and Huai River in China [14].

LED fluorescence can liberate light of projected shading that traditional techniques usually require. This brings down expenses and proven to be highly productive. In this method, a bundle of LED is used as the light emitter. An outer reflector is needed for glowing and collecting light from fluorescent sources. At the point where darkening is needed and it is utilized, LEDs don't change their shading tint as the intensity is brought down. This is in contrast to radiant lights, which turn yellow. LEDs are perfectly applicable, in cases where on- 
off cycling is required as, unlike fluorescent lights that wear out fast when cycled or high-intensity discharge (HID) lights that usually need some time before starting again, LEDs could be on-off at very high toggling frequencies. LEDs, being strong electrical components, are hard to harm with outside stun. Fluorescent and radiant globules are effortlessly broken if subjected to outside stun.

At present, LEDs are costlier, measured in cost per lumen, than many conventional lighting approaches. The excess cost comes from the generally low lumen yield, combined with the expenses of the hardware and battery supplies required. Moreover, LED operates to an extent depends on the temperature of the working ambience. Driving the LED in a high-temperature environment may bring about overheating of the LED, inevitably causing the component failure [15].

\subsection{Sludge Volume Index (SVI) Sensors}

Deficiency identification is a standout amongst those centre examination zones in a wastewater treatment plant. A flaw line identification system, incorporating the foreseeing plant deficiency identification is a standout amongst those centre examination zones in a wastewater treatment plant. A flaw line identification system, incorporating the foreseeing plant shortcoming finding method, will be recommended and connected with a wastewater treatment plant. For such cases, a fuzzy neural network (FNN), will be an ideal solution that incorporates SVI predictions. A method has been proposed for highly efficient detection of SVI using SVI sensor in 2014 by Honggui et al. [16]. The main goal of this study was to implement a system including online sensors with a better fault determining efficiency.

The execution of the versatile foreseeing plant in light of FNN assures that this proposal can upgrade the ability of the SVI foreseeing plant with respect to wastewater treatment efficacy [17]. The examination outcomes indicate that the versatile foreseeing plant has the ability on exact SVI predictions over the opposite routines. An issue finding method, by considering the after-effects of the foresight and the SVI sensor, has been formed to uncover the faults web [18]. Test effects demonstrate that recommended deficiency identification framework will be about identifying those exact faults of SVI sensor, which will be vital on stay with the safe and prudent operation of WWTP. Future fills in will coordinate the deficiency signs under the framework control and aggravate those safe states for wastewater treatment plant.

\subsection{Non-thermal Plasmas}

Water in pharmaceutical compounds is a significant problem affecting the environment. Impacts of plasmacatalytic on wastewater (thermal ooze dryer emissions) have been mulled over to field tests in many areas and the method proposed for it showed its possibility for deodorization. Many research outcomes have shown the cause as the presence of plasma and organic compounds in the water [19].

The waste gas medicine provided for wastewater medicine plants introduced methods need to be performed in genuine conditions. In the study by Hołub et al [20], it has been proved that the technologies assisted with plasma can be a good solution for removing the wastewater odour [20]. They combined the sensors with the plasma scrubbing catalysts. With the help of olfactometry, it was possible to reduce the odorous compounds in wastewater. But with reducing one compound that caused odour, it resulted in the development of another undesired waste compound that caused odour. Thus, Hołub et al. [20] concluded that treatment plant using the gas treatment should always be a blending of minimum two or more technologies [20]. A similar system that has proven its stability and reliability has been implemented in Switzerland [21]. This system reduced almost $95 \%$ of the wastewater odour for a long period.

\subsection{UV/V is Spectrophotometers}

For monitoring the quality of water in different areas and conditions, UV/Vis spectrophotometers have been widely used. As per the reported study [22], for a certain water matrix, a number of methods have been 
evaluated and UV/Vis spectrophotometers have provided local and global calibration [22]. The research has concluded that the local calibration is very much preferable and accurate [22]. The local calibration promises a high stability, high precision results. The study has mostly used local calibration method. The calibrated UV/Vis spectrophotometers were used for detecting TSS and dissolved COD concentrations. The selection of this calibration method is based on the settlement robustness, complexity, and accuracy. In this study, the researchers have used the root mean square error and $\mathrm{r} 2$ criterion to calculate the results. The results were found to be consistent.

\subsection{Electronic Noses (E-nose)}

In Italy, due to the stringent authoritarian regulations, several solutions emerged during the last decade to detect and monitor wastewater odour. One such is the electronic nose, which is low-cost, and user-friendly to detect volatiles and conduct chemical analysis of air [23]. One of the major issue of this technique from the beginning was the evaluation of the discriminant capacity of the sensor array under in-field and working conditions. Giungato et al. [23] studied various modes of odours emission from a waste management plant under the observation of electronic noses by integrating the results with information collected from dynamic olfactometry and gas chromatography-mass spectrometry/ olfactometry. They have detected three fundamental odours in waste management plant; biogas, mechanical treated municipal solid wastes having low organic content and sludge pressed and dehydrated from urban wastewater. Among these three basic odours, the most impacting odour was the sludge pressed and dehydrated from urban wastewater due to some aromatics such as 1,3,5-trimethylbenzene, aliphatic hydrocarbons, terpenes and some sulphur volatiles such as methyl disulphide, carbon disulphide, and dimethyl trisulphide. The source of odour impact was the by-product of mechanical treated municipal solid wastes with low organic content. The source showed the emission of some aromatics particularly 1,3,5-trimethylbenzene aliphatic hydrocarbons and terpenes. The detection efficiency was compared with the outputs of two other commercially available e-Noses available in the market. The results were comparable thus, it could be concluded that the method is applicable with good accuracy. The method is commercially tangible and very useful for odour recognition thus, suitable for implementation in the odour control management system. The result of this study can be used in the reduction of odour problems and can help in future to develop integrated sensor signals for atmospheric dispersion models.

\section{Soft-Sensors}

Strenuous measurement conditions and the high cost of hardware sensors motivated researchers to develop software sensors (soft sensors) in the recent years. A soft sensor computes a variable that may be complex to measure (primary variable) using simple or easy-to-measure parameters (secondary variable) together with the use of mathematical models [24]. Estimation or prediction of a hard-to-measure variable by the soft sensors using easy-to-measure variables is also due to the lack of reliable online measurements, where analysis of important variables is done offline in laboratory causing delays in response, thus making it unsuitable for online monitoring of process variable such as that in a wastewater treatment plant.

\subsection{Applications of Soft-sensors}

Primary variables in wastewater quality management include concentration of nitrates $\left(\mathrm{NO}_{3}\right)$ and total nitrogen (TN), ammonia $\left(\mathrm{NH}_{3}\right)$, phosphates $\left(\mathrm{PO}_{4}{ }^{3-}\right)$ and total phosphorus (TP), chemical oxygen demand (COD), biological oxygen demand (BOD), suspended solids (SS) and other process variables such as sludge blanket level [25]. Measurement of these quality indices are often complex and although such sensors are available, the setup cost and maintenance expenditure are usually high. Routine online measurements of secondary variables offer an inexpensive approach to extract information on primary variables to facilitate monitoring of process as well as instruments. Common secondary variables include temperature, pressure, level 
measurements, conductivity, $\mathrm{pH}$, turbidity, and probably dissolved oxygen (DO). In order to perform estimation of primary variables, models are developed in which correlation between primary and secondary variables are reconstructed [25].

Table 1. Soft-sensor Application in Wastewater Quality Management

\begin{tabular}{|c|c|c|c|}
\hline Quality Indices & Method & WWTP Process & Ref. \\
\hline COD, BOD5, TN & ANN & Simulation, urban & [26] \\
\hline BOD, COD, TSS & ANN & Full-scale, biological in Doha West & [27] \\
\hline $\begin{array}{l}\text { BOD, COD, TNC, TA, } \\
\text { TP }\end{array}$ & $\begin{array}{l}\text { Hybrid first principles } \\
\text { NN }\end{array}$ & Full-scale, biological textile industry & [28] \\
\hline $\mathrm{TN}, \mathrm{TP}$, total COD & Adaptive PCA+ ANN & $\begin{array}{l}\text { Full-scale, domestic rural biological } \\
\text { in Korea }\end{array}$ & [29] \\
\hline $\begin{array}{l}\text { BOD, MLSS, COD, } \\
\text { pH, DO }\end{array}$ & FGCNN & Simulation, biological & {$[30]$} \\
\hline $\begin{array}{l}\mathrm{BOD}, \mathrm{COD}, \mathrm{SS}, \mathrm{EC}, \\
\text { temperature }\end{array}$ & GRNN, MLR & $\begin{array}{l}\text { Full-scale, rural domestic in east } \\
\text { Algeria }\end{array}$ & {$[31]$} \\
\hline COD, TN, TSS & $\begin{array}{l}\text { Optimal neural network } \\
\text { (ANN + PCA) }\end{array}$ & Simulation, large scale municipal & {$[32]$} \\
\hline BOD5 & Deep Neural Network & benchmark testbed, biological & {$[33]$} \\
\hline $\mathrm{SS}, \mathrm{COD}, \mathrm{pH}$ & ANFIS & ASP in CSBR, hospital & {$[34]$} \\
\hline Carbon, nitrogen & ANFIS & Full scale, sugar industry & {$[35]$} \\
\hline COD & ANFIS & Full scale, domestic & {$[36]$} \\
\hline BOD5, COD & ANFIS & Simulation, paper mill industry & {$[37]$} \\
\hline $\mathrm{COD}, \mathrm{PO}_{4}{ }^{3-}, \mathrm{NO}_{3}{ }^{-}$ & GA-ANFIS & Lab-scale, biological & [38] \\
\hline COD, TN, TP & GA-ANFIS & $\begin{array}{l}\text { Full scale, biological in Daewoo, } \\
\text { Korea }\end{array}$ & [39] \\
\hline RBB concentration & CCD, MLR, ANFIS & Textile industry & {$[40]$} \\
\hline SS, COD & ANFIS + PCA & Full scale, paper mill industry & {$[41]$} \\
\hline 20 important variables & SEVA (VBPCA+RVM) & $\begin{array}{l}\text { Simulation, highly instrumented } \\
\text { Full-scale, lowly instrumented }\end{array}$ & {$[42]$} \\
\hline BOD5 & SEVA (PCA+JIT) & Simulation, ASP & [43] \\
\hline $\mathrm{NO}_{3}^{-}$ & Sensor array & Full-scale, municipal & [44], [45] \\
\hline $\mathrm{NO} 3-\mathrm{N}$ & Sensor rank & Full-scale, municipal & [46] \\
\hline
\end{tabular}


Soft-sensor has found successful applications to determine quality indices for wastewater by monitoring of related parameters in various research efforts. A summary of soft-sensor application in wastewater quality management considered in this paper is shown in Table 1, in which only data-derived soft sensors are reviewed. Data-derived soft sensor is basically an input-output model, in which prediction models are constructed from the process data [25]. It is becoming more popular since routine real-time measurement and data collection in many modern wastewater treatment plants (WWTPs) permits the use of data-derived modelling as an alternative approach to the design of soft-sensor.

\subsection{Neural Network Soft-sensors}

Earlier works include data-derived artificial neural network (ANN) estimation of quality parameters such as effluent ammonium $\left(\mathrm{NH}_{4}\right.$ ), 5-day BOD reading (BOD5) and total suspended solids (TSS) which show good results in comparison to a mechanistic model estimate of WWTP. ANN method reduces the simulation time significantly relative to mechanistic model predictions in developing urban wastewater management plan. The accuracy of prediction is sufficient for the application although prediction of effluent COD and TN concentrations was a bit less satisfactory [26]. The influent data for ANN training was generated using mechanistic model. Another similar work was done using real data obtained from Doha West WWTP to predict the operational parameters, which are COD, BOD, and TSS [27]. The accuracy obtained was considered good with the additional development of graphical user interface (GUI) to facilitate the calculation of ANN estimation for a given plant input and prevents improper use of the soft-sensor.

In the treatment of textile wastewater, in which multiple biological, chemical as well as heavy metal parameters as a quality indicator are predicted using hybrid-first principles neural network model giving a sufficiently good accuracy [28]. Neural network model that predicts the biological decomposition kinetics for every contaminant is combined with the mass-balance equation of conventional model.

A system for remote monitoring in real time was developed based on adaptive principal component analysis (PCA) and neural network software sensor to predict effluent COD, nitrogen $(\mathrm{N})$ and phosphorous (P) concentration for three domestic biological WWTPs in Korea [29]. The remote monitoring system provides efficient operational support for rural WWTP with low running cost by allowing real-time transfer of knowledge to local plant operators from experts at a remote location.

A fast-growing cascade neural network provides an improvement over the traditional ANN method due to extremely fast network learning by using simple ways to update weights and select hidden units. The nonlinear correlation between easy to measure variables that include DO, COD and $\mathrm{pH}$ and the estimated BOD in a biological WWTP was well presented. The model developed using this method was proved to be fast and reliable as shown by simulative results of BOD estimation [30].

Prediction of effluent BOD at Sidi Marouane Wastewater Plant in the eastern part of Algeria using a nonlinear model based on generalized regression neural network (GRNN) results in better predictive capability in comparison to a standard model of multiple linear regression (MLR) [31]. Five quality variables for effluent wastewater including $\mathrm{COD}, \mathrm{SS}, \mathrm{pH}$, temperature and electrical conductivity (EC) were used in building the GRNN and MLR models. GRNN has the potential to be a simple and powerful alternative technique in developing software sensor.

The optimal neural network was used together with PCA to develop soft sensor in the application for an activated sludge process (ASP) of a large-scale municipal WWTP in simulation framework for prediction of COD, TSS and TN content [32]. Efficient on-line estimation of nutrient concentration can improve effluent quality measurements in WWTP without having to purchase expensive but sometimes unreliable instruments, thus an economical improvement of the plant performance.

A hybrid of deep neural network and genetic algorithm (GA) was used in developing a soft-sensor to predict BOD5 in a biological WWTP. The deep neural network is considered suitable for process monitoring, fault diagnosis and advanced control of WWTP due to ability in dealing with a complex situation that usually occurs in a WWTP such as sudden changes in process state which could reduce the accuracy of prediction for soft- 
sensor [33].

\subsection{Neuro-fuzzy Inference System (ANFIS) Soft Sensors}

Traditional ANN method of prediction is known to suffer few problems such as the possibility of trapping in the local minima, large amount of training time and the challenge in determining the best architecture to ensure the least error of prediction is obtained. Also, the internal relation between the parameters involved in the model is unknown. To overcome these drawbacks, hybrid neural network approaches are often used. The most commonly used approach used is adaptive neuro-fuzzy inference system (ANFIS).

ANFIS approach applied to an ASP in a continuous sequence batch reactor (CSBR) for hospital WWTP to first establish a correlation between influent and effluent quality parameters, and later to estimate the effluent quality indices consisting of SS, COD, and $\mathrm{pH}$ [34]. The result indicates a good effluent quality estimate using ANFIS that statistically outperforms ANN. Works adopting similar approaches with comparable outcome includes prediction of carbon and nitrogen from sugar production industry wastewater in a full-scale treatment plant and COD prediction in a full-scale domestic WWTP [35], [36]. Results indicate the suitability of ANFIS modelling technique in describing the correlation between wastewater quality indices.

Soft-sensor using ANFIS was developed to establish the dynamic relationship between removal rates of BOD5 and COD with dosages of coagulant and coagulant aid in a treatment plant for wastewater from paper mill industry. The enhanced learning capability of this method enables adaptation of the system to various operating conditions, thus successfully models the nonlinear relationship of chemical dosages with pollutants removal rate which is used as the wastewater quality control index [37].

A soft sensor based on GA-ANFIS using online measurements of DO, oxidation-reduction potential (ORP), and $\mathrm{pH}$ as input data gives a good estimate of effluent $\mathrm{COD}$ and nutrient concentrations $\left(\mathrm{PO}_{4}{ }^{3-}, \mathrm{NO}_{3}{ }^{-}\right)$as shown by simulation results [38]. It was used in the application of nutrient removal process for biological wastewater treatment and a lab-scale reactor was used for data collection. Combination of GA and backpropagation (BP) algorithm for hybrid learning shows robustness and good generalization capability for prediction, thus gives GA-ANFIS superior performance in comparison to slow convergence and long learning time of neuro-fuzzy approach. This hybrid algorithm has the potential for effective application in anoxic/oxic processes for real-time prediction of nutrient dynamics.

Hybrid soft sensor based on GA-ANFIS also shows satisfactory performance in prediction of effluent nutrient concentration at a full-scale nutrient removal WWTP in Daewoo, Korea [39]. The nonlinear relationship between influent pollutant variables and effluent variables in this biological WWTP was effectively established with the individual model developed for each of the effluent parameters to be predicted, namely COD, TP, and TN. Other measured process parameters used in developing the soft sensor are influent variables including TSS, BOD, COD, TN, and TP.

ANFIS model prediction of Remazol Black B (RBB) dye concentrations in industrial textile wastewater based on measurements from plastic optical fibre (POF) sensor demonstrate higher accuracy compared to Central Composite Design (CCD) and MLR [40]. All three models recorded fairly high accuracy in this study on the performance of POF sensor having various diameters in detecting RBB concentration, which could be useful for wastewater plant design at a preliminary stage. Models for estimation of COD and SS removal were developed using ANFIS for the application of full-scale paper mill wastewater process treatment plant in China [41]. In this work, the input variable dimension was reduced using PCA method and results prove the developed ANFIS network is capable to predict the effluent concentration.

\subsection{Self-validating Soft Sensors}

Despite numerous successful modelling of wastewater treatment process and corresponding prediction of the effluent quality index, the application of soft sensors is not extensive. Unreliable data in the input variables such as missing values, faulty sensor data, and noises deteriorates the estimates of soft sensors as the online 
measurements of these values and the process model is used to infer the quality indices. Missing measurements and irregular sampling of data are a common occurrence especially in the tough conditions of biological wastewater treatment plants due to hardware sensor failure, system malfunction or even routine maintenance [42]. Self-validating (SEVA) soft sensor offers a solution to this problem in which unreliable or abnormal data could be identified and even reconstructed once recognized before it is used for soft sensor prediction.

A Variable Bayesian Principal Component Analysis (VBPCA) model was used to validate measured data prior to the development of prediction model using Relevant Vector Machine (RVM). 20 important variables were selected for constructing the model. The soft-sensor was tested in the simulation of two WWTP with different process characteristics to represent a highly instrumented plant with frequent data sampling and a lowly instrumented plant where data sampling was at an interval of one day. Results proved although missing values and faulty data are present, a better estimation of effluent BOD is possible using this probabilistic selfvalidating soft sensor [42].

SEVA soft sensor has been applied to estimate effluent BOD5 of an ASP in WWTP for organic matter and nutrient removal. PCA model was developed prior to prediction using Just-In-Time (JIT) model. PCA model not only validates and reconstructs the input data but also generates other types of soft-sensor outputs including prediction values, output sensor status, input sensor status, uncertainty values and validated measurements. With an ability to indicate sensor status in addition to input and output sensor validation, this soft sensor framework could be the basis for reliable and robust soft-sensor development [43].

An array of soft-sensor for the estimate of nitrite concentration provided a reliable backup system in the case of downtime and hardware sensor malfunction in the denitrifying post-filtration unit of a municipal WWTP in Helsinki, Finland [44], [45]. Experimental results confirm the soft sensor is effective in providing an inexpensive support to existing conventional analytical instrumentation to perform validation on existing analysis and as an alternative to out-of-order instruments. Results of feasibility analysis over a wide range of operating condition of the soft sensor show potential for implementation in the plant's on-line monitoring and control system.

A proposed system that ranks the measurements and estimates shall enable the complementary use of hardware measurement and soft sensor prediction to determine nitrate-nitrogen (NO3_N) concentrations in the denitrifying post-filtration unit of a municipal WWTP [46]. Automatic changing between measurements from hardware instruments and corresponding software estimate was done using switching procedure based on the ranking of hardware sensor reading and output data from ten soft sensors.

\section{Conclusions}

This paper critically reviews the pros and cons of existing physical sensors and soft sensors that can be employed in the quality management of effluents at wastewater treatment plants. The effectiveness of sensor measurement in terms of accuracy, selectivity, cost-effectiveness, and viability under various operational conditions has been discussed. The information helps proper selection of sensor technologies for a given application in wastewater quality management. The compilation and analysis of the concurrent information paves the way for researchers in developing better sensors for the future, which may overcome the existing scientific challenges at present. 


\begin{tabular}{|c|c|}
\hline \multicolumn{2}{|c|}{ Nomenclature } \\
\hline ANFIS & adaptive neuro-fuzzy inference \\
\hline ANN & artificial neural network \\
\hline ASP & activated sludge process \\
\hline BOD & biological oxygen demand \\
\hline BOD5 & 5-day biological oxygen demand reading \\
\hline $\mathrm{BP}$ & back-propagation \\
\hline $\mathrm{CCD}$ & central composite design \\
\hline $\mathrm{COD}$ & chemical oxygen demand \\
\hline CSBR & continuous sequence batch reactor \\
\hline DO & dissolved oxygen \\
\hline DOC & dissolved organic carbon \\
\hline DOM & dissolved organic matter \\
\hline $\mathrm{EC}$ & electrical conductivity \\
\hline EEM & excitation-emission matrix \\
\hline FGCNN & fast growing cascade neural network \\
\hline FNN & fuzzy neural network \\
\hline GA & genetic algorithm \\
\hline GRNN & generalized regression neural network \\
\hline GUI & graphical user interface \\
\hline HID & high-intensity discharge \\
\hline JIT & Just-In-Time \\
\hline LED & light emitting diode \\
\hline MLR & multiple linear regression \\
\hline MLSS & mixed liquor suspended solid \\
\hline $\mathrm{N}$ & nitrogen \\
\hline $\mathrm{NH}_{3}$ & ammonia \\
\hline $\mathrm{NH}_{4}$ & effluent ammonium \\
\hline $\mathrm{NO}_{3}$ & nitrates \\
\hline $\mathrm{NO} 3-\mathrm{N}$ & nitrate-nitrogen \\
\hline ORP & oxidation-reduction potential \\
\hline OUR & oxygen uptake rate \\
\hline $\mathrm{P}$ & phosphorous \\
\hline PCA & principal component analysis \\
\hline POF & plastic optic fibre \\
\hline $\mathrm{PO}_{4}^{3-}$ & phosphates \\
\hline RBB & Remazol Black B \\
\hline RVM & Relevant Vector Machine \\
\hline SEVA & self-validating \\
\hline SS & suspended solids \\
\hline SVI & sludge volume index \\
\hline TA & tannins \\
\hline TOC & total organic carbon \\
\hline $\mathrm{TN}$ & total nitrogen \\
\hline TNC & total nitrocompounds \\
\hline TP & total phosphorus \\
\hline TSS & total suspended solids \\
\hline UV & ultraviolet \\
\hline
\end{tabular}


Nomenclature (continued)

VBPCA Variable Bayesian Principal Component Analysis

WWTP wastewater treatment plant

\section{Acknowledgement}

The authors would like to thank the Faculty of Engineering, Universiti Putra Malaysia for this multidisciplinary environmental engineering project. The IPS Grant GP-IPS/2016/9506500 through which this project has been funded is greatly acknowledged

\section{References}

[1] Ł. Guz, G. Łagód, K. Jaromin-Gleń, Z. Suchorab, H. Sobczuk, and A. Bieganowski, "Application of gas sensor arrays in assessment of wastewater purification effects," Sensors (Switzerland), vol. 15, no. 1, pp. 1-21, 2015.

[2] P. A. Vanrolleghem and D. S. Lee, "On-line monitoring equipment for wastewater treatment processes: State of the art," Water Sci. Technol., vol. 47, no. 2, pp. 1-34, 2003.

[3] N. A. Abdullah, S. Ramli, N. H. Mamat, S. Khan, and C. Gomes, "Chemical And Biosensor Technologies for Wastewater Quality Management," Int. J. Adv. Res. Publ., vol. 1, no. 6, pp. 1-10, 2017.

[4] A. R. Dahiru, N. B. Nordin, M. N. Ishak, M. S. B. Mislan, and C. Gomes, "Chemical Method for Wastewater Management: Developments of Fenton Process," Int. J. Adv. Res. Publ., vol. 1, no. 3, pp. 123-137, 2017.

[5] B. Petrie, R. Barden, and B. Kasprzyk-Hordern, "A review on emerging contaminants in wastewaters and the environment: Current knowledge, understudied areas and recommendations for future monitoring," Water Res., vol. 72, no. 0, pp. 3-27, 2015.

[6] S. C. Anijiofor, N. A. M. Jamil, S. Jabbar, S. Sakyat, and C. Gomes, "Aerobic and Anaerobic Sewage Biodegradable Processes : The Gap Analysis Aerobic and Anaerobic Sewage Biodegradable Processes : The Gap Analysis," Int. J. Res. Environ. Sci., vol. 3, no. 3, pp. 9-19, 2017.

[7] F. C. Silva, M. A. S. Martins, L. Bilro, R. N. Nogueira, I. Capela, and J. J. Keizer, "Optical Fiber Technology for Monitoring and Preventing Biomass Washout from Bioreactors: A Case Study with a Sequencing Batch Reactor (SBR)," Water. Air. Soil Pollut., vol. 226, no. 176, pp. 1-11, 2015.

[8] N. Paoprasert, S. Srisawadi, J. Munnae, V. Champeeratana, and N. Techapreechawong, "Optimization of the rubber coagulation process for wastewater treatment in latex separator disc cleaning system," in 2015 IEEE International Conference on Industrial Engineering and Engineering Management (IEEM), 2015, pp. 1347-1351.

[9] P. M. Yeole and M. R. Wakchaure, "Use Of Kevlar Fabric To Enhance Flexural Strength Of RC Beams," Int. J. Eng. Res. Technol., vol. 2, no. 6, pp. 2250-2257, 2013.

[10] R. K. Henderson, A. Baker, K. R. Murphy, A. Hambly, R. M. Stuetz, and S. J. Khan, "Fluorescence as a potential monitoring tool for recycled water systems : A review," Water Res., vol. 43, no. 4, pp. 863881, 2009.

[11] B. Chen and P. Westerhoff, "Predicting disinfection by-product formation potential in water," Water Res., vol. 44, no. 13, pp. 3755-3762, 2010.

[12] L. Yang, D. Kim, H. Uzun, T. Karanfi, and J. Hur, "Assessing trihalomethanes (THMs) and Nnitrosodimethylamine (NDMA) formation potentials in drinking water treatment plants using 
fluorescence spectroscopy and parallel factor analysis," Chemosphere, vol. 121, pp. 84-91, 2015.

[13] S. K. L. Ishii and T. H. Boyer, "Behavior of reoccurring parafac components in fluorescent dissolved organic matter in natural and engineered systems: A critical review," Environ. Sci. Technol., vol. 46, no. 4, pp. 2006-2017, 2012.

[14] W. Li et al., "Developing LED UV fluorescence sensors for online monitoring DOM and predicting DBPs formation potential during water treatment," Water Res., vol. 93, pp. 1-9, 2016.

[15] W. T. Li et al., "Application of portable online LED UV fluorescence sensor to predict the degradation of dissolved organic matter and trace organic contaminants during ozonation," Water Res., vol. 101, pp. 262-271, 2016.

[16] H. Honggui, L. Ying, and Q. Junfei, "A fuzzy neural network approach for online fault detection in waste water treatment process," Comput. Electr. Eng., vol. 40, no. 7, pp. 2216-2226, 2014.

[17] G. Min, G. Ya-nan, and H. Hong-gui, "A SVI soft sensor model based on improved PSO-Elman neural network," in Proceeding of the 11th World Congress on Intelligent Control and Automation, 2014, pp. $3545-3550$.

[18] A. W. Alattabi, C. Harris, R. Alkhaddar, A. Alzeyadi, and K. Hashim, "Treatment of Residential Complexes' Wastewater using Environmentally Friendly Technology,” Procedia Eng., vol. 196, no. June, pp. 792-799, 2017.

[19] M. Hijosa-Valsero, R. Molina, A. Montràs, M. Müller, and J. M. Bayona, "Decontamination of waterborne chemical pollutants by using atmospheric pressure nonthermal plasma: a review," Environ. Technol. Rev., vol. 3, no. 1, pp. 71-91, 2014.

[20] M. Hołub, R. Brandenburg, H. Grosch, S. Weinmann, and B. Hansel, "Plasma supported odour removal from waste air in water treatment plants: An industrial case study," Aerosol Air Qual. Res., vol. 14, no. 3, pp. 697-707, 2014.

[21] M. Mulder, D. Antakyali, and S. Ante, "Costs of Removal of Micropollutants from Effluents of Municipal Wastewater Treatment Plants - General Cost Estimates for the Netherlands based on Implemented Full Scale Post Treatments of Effluents of Wastewater Treatment Plants in Germany and Switzerland," 2015.

[22] M. Lepot et al., "Calibration of UV/Vis spectrophotometers: A review and comparison of different methods to estimate TSS and total and dissolved COD concentrations in sewers, WWTPs and rivers," Water Res., vol. 101, pp. 519-534, 2016.

[23] P. Giungato et al., "Improving recognition of odors in a waste management plant by using electronic noses with different technologies, gas chromatography-mass spectrometry/olfactometry and dynamic olfactometry," J. Clean. Prod., vol. 133, pp. 1395-1402, 2016.

[24] L. Åmand, G. Olsson, and B. Carlsson, “Aeration control - A review,” Water Sci. Technol., vol. 67, no. 11, pp. 2374-2398, 2013.

[25] H. Haimi, M. Mulas, F. Corona, and R. Vahala, "Data-derived soft-sensors for biological wastewater treatment plants: An overview," Environ. Model. Softw., vol. 47, pp. 88-107, 2013.

[26] B. Ráduly, K. V. Gernaey, A. G. Capodaglio, P. S. Mikkelsen, and M. Henze, "Artificial neural networks for rapid WWTP performance evaluation: Methodology and case study," Environ. Model. Softw., vol. 22, no. 8, pp. 1208-1216, 2007.

[27] F. S. Mjalli, S. Al-Asheh, and H. E. Alfadala, "Use of artificial neural network black-box modeling for the prediction of wastewater treatment plants performance," J. Environ. Manage., vol. 83, no. 3, pp. 329-338, 2007.

[28] E. Molga, R. Cherbański, and L. Szpyrkowicz, "Modeling of an industrial full-scale plant for biological treatment of textile wastewaters: Application of neural networks," Ind. Eng. Chem. Res., vol. 45, no. 3, pp. 1039-1046, 2006.

[29] M. W. Lee, S. H. Hong, H. Choi, J.-H. Kim, D. S. Lee, and J. M. Park, "Real-time remote monitoring of small-scaled biological wastewater treatment plants by a multivariate statistical process control and neural network-based software sensors," Process Biochem., vol. 43, no. 10, pp. 1107-1113, 2008. 
[30] L. I. L. Fanjun, Q. Junfei, and Z. Wei, “A fast growing cascade neural network for BOD estimation," in Proceedings of the 34th Chinese Control Conference, 2015, pp. 3417-3422.

[31] S. Heddam, H. Lamda, and S. Filali, "Predicting Effluent Biochemical Oxygen Demand in a Wastewater Treatment Plant Using Generalized Regression Neural Network Based Approach: A Comparative Study," Environ. Process., vol. 3, no. 1, pp. 153-165, 2016.

[32] J. Fernandez de Canete, P. Del Saz-Orozco, R. Baratti, M. Mulas, A. Ruano, and A. Garcia-Cerezo, "Soft-sensing estimation of plant effluent concentrations in a biological wastewater treatment plant using an optimal neural network," Expert Syst. Appl., vol. 63, pp. 8-19, 2016.

[33] Y. Qiu, Y. Liu, and D. Huang, "Date-driven soft-sensor design for biological wastewater treatment using deep neural networks and genetic algorithms," J. Chem. Eng. Japan, vol. 49, no. 10, pp. 925-936, 2016.

[34] T. Y. Pai et al., "Using fuzzy inference system to improve neural network for predicting hospital wastewater treatment plant effluent," Comput. Chem. Eng., vol. 33, no. 7, pp. 1272-1278, 2009.

[35] G. Civelekoglu, A. Perendeci, N. O. Yigit, and M. Kitis, "Modeling carbon and nitrogen removal in an industrial wastewater treatment plant using an adaptive network-based fuzzy inference system," Clean Soil, Air, Water, vol. 35, no. 6, pp. 617-625, 2007.

[36] G. Civelekoglu, N. O. Yigit, E. Diamadopoulos, and M. Kitis, "Modelling of COD removal in a biological wastewater treatment plant using adaptive neuro-fuzzy inference system and artificial neural network," Water Sci. Technol., vol. 60, no. 6, pp. 1475-1487, 2009.

[37] H. Mingzhi, Y. Ma, W. Jinquan, and W. Yan, "Simulation of a paper mill wastewater treatment using a fuzzy neural network," Expert Syst. Appl., vol. 36, no. 3 PART 1, pp. 5064-5070, 2009.

[38] M. Huang, Y. Ma, J. Wan, and X. Chen, "A sensor-software based on a genetic algorithm-based neural fuzzy system for modeling and simulating a wastewater treatment process," Appl. Soft Comput. J., vol. 27, pp. 1-10, 2015.

[39] H. Liu, M. Huang, and C. Yoo, "A fuzzy neural network-based soft sensor for modeling nutrient removal mechanism in a full-scale wastewater treatment system," Desalin. Water Treat., vol. 51, no. 31-33, pp. 6184-6193, 2013.

[40] S. S. Chong, a. R. Abdul Aziz, S. W. Harun, H. Arof, and S. Shamshirband, "Application of multiple linear regression, central composite design, and ANFIS models in dye concentration measurement and prediction using plastic optical fiber sensor," Measurement, vol. 74, pp. 78-86, 2015.

[41] J. Wan et al., "Prediction of effluent quality of a paper mill wastewater treatment using an adaptive network-based fuzzy inference system," Appl. Soft Comput., vol. 11, no. 3, pp. 3238-3246, 2011.

[42] Y. Liu, J. Chen, Z. Sun, Y. Li, and D. Huang, "A probabilistic self-validating soft-sensor with application to wastewater treatment," Comput. Chem. Eng., vol. 71, pp. 263-280, 2014.

[43] L. Yiqi, H. Daoping, and L. Zhifu, "A SEVA soft sensor method based on self-calibration model and uncertainty description algorithm," Chemom. Intell. Lab. Syst., vol. 126, pp. 38-49, 2013.

[44] M. Mulas, F. Corona, H. Haimi, L. Sundell, M. Heinonen, and R. Vahala, "Nitrate estimation in the denitrifying post-filtration unit of a municipal wastewater treatment plant: the Viikinmaki case," Water Sci. Technol., vol. 65, no. 8, pp. 1521-1529, 2012.

[45] F. Corona, M. Mulas, H. Haimi, L. Sundell, M. Heinonen, and R. Vahala, "Monitoring nitrate concentrations in the denitrifying post-filtration unit of a municipal wastewater treatment plant," $J$. Process Control, vol. 23, no. 2, pp. 158-170, 2013.

[46] H. Haimi, F. Corona, M. Mulas, L. Sundell, M. Heinonen, and R. Vahala, "Shall we use hardware sensor measurements or soft-sensor estimates? Case study in a full-scale WWTP," Environ. Model. Softw., vol. 72, pp. 215-229, 2015. 


\section{Authors' Profiles}

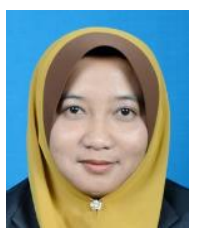

Nor Hana Mamat holds a B.Eng in Telecommunication from Universiti Malaya and M. Eng. in Electrical (Mechatronics and Automatic Control) from Universiti Teknologi Malaysia. An academic staff in TATI Universiti College, Terengganu, Malaysia, she is currently on study leave doing PhD in Control Systems Engineering at Universiti Putra Malaysia. Her research interest is control system in soft-sensor modelling for bioprocess.

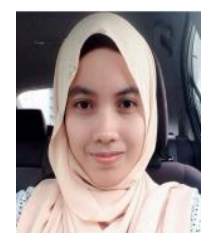

Saliza Ramli holds a B. Eng in Electrical and Electronic from Akita University, Japan and M.Sc in Information and Telecommunication Engineering from Universiti Teknologi MARA, Malaysia. She is currently a fellow at Universiti Teknikal Malaysia Melaka, Malaysia. Her research interest is signal processing in biomedical application.

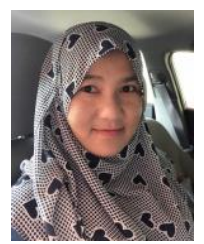

Nur Arymaswati Abdullah serves as s researcher at Malaysian Nuclear Agency. Currently, she is doing he PhD in Control System Engineering at Universiti Putra Malaysia. She holds a B. Eng in Electrical, Electronics and System from Universiti Kebangsaan Malaysia and M. Eng. in Electrical (Mechatronics and Automatic Control) from Universiti Teknologi Malaysia. Her research interest is control systems in process modelling and control.

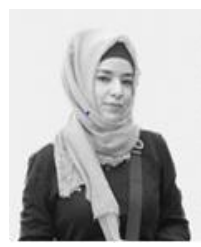

Samia Khan obtained her B. Tech in Information Technology from College of Engineering and Technology, Baba Ghulam Shah Badshah University, India in July 2014. She recently completed her Master of Science Degree in Computer Networks from Faculty of Engineering, Universiti Putra Malaysia.

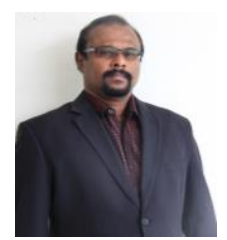

Chandima Gomes is a professor of electrical engineering and researcher in high voltage engineering and lightning protection at Universiti Putra Malaysia. $\mathrm{He}$ is also an expert in power and energy, electromagnetic interference and compatibility and occupational safety management. He has conducted over 120 training programs in 12 countries so far. Chandima has published over 300 research papers and several books on his expertise. He obtained a First Class Degree in Physics from the University of Colombo in 1993. He has done his PhD (1999) and postdoctoral research on lightning protection and high voltage engineering at Uppsala University, Sweden.

How to cite this paper: Nor Hana Mamat, Saliza Ramli, Nor Arymaswati Abdullah, Samia Khan, Chandima Gomes,"Physical and Soft Sensor Technologies for Wastewater Quality Management", International Journal of Education and Management Engineering(IJEME), Vol.8, No.6, pp.1-14, 2018.DOI: 10.5815/ijeme.2018.06.01 